\title{
Perception and knowledge of mothers on causes and treatment of rickets associated knee deformity in Ile-Ife, Osun State, Nigeria
}

\author{
O.O. ADEGBEHINGBE ${ }^{1 *}$, C.A. ADEGBENRO2, I.O. AWOWOLE², P.O. TOMORI² \\ and O.A. OYELAMI ${ }^{3}$ \\ ${ }^{1 *}$ Department of Orthopaedic Surgery and Traumatology, Obafemi Awolowo University, Ile-Ife, Osun State, Nigeria \\ ${ }^{2}$ Department of Community Health, Obafemi Awolowo University, Ile-Ife, Osun State, Nigeria \\ ${ }^{3}$ Department of Paediatrics and Child Health, Obafemi Awolowo University, Ile-Ife, Osun State, Nigeria
}

\begin{abstract}
This descriptive cross-sectional community-based study was carried out in Ile-Ife, Nigeria to assess the knowledge of mother's on the aetiology of rickets associated knee deformities and the cultural perception of its treatment. Data collection was done using interviewer based semi structured questionnaires. A total of 464 questionnaires were administered with a response rate of $86.9 \%$. Over half $(59.8 \% ; \mathrm{N}=241)$ and $36.5 \%$ (147) of the mothers were aware of children with knee deformity and rickets, respectively. Ninety-one $(22.6 \%)$ mothers had the correct knowledge and perception of the true meaning of rickets. Rickets associated knee deformity aetiology was wrongly perceived to be mainly hereditary (53.8\%), cancer $(50.9 \%)$ and bone infection $(48.1 \%)$. Very low proportions of mothers had correct knowledge on the causes of rickets such as inadequate exposure to sunshine $(21.3 \%)$ or inadequate intake of calcium $(21.1 \%)$. The knowledge of aetiology of rickets was influenced by education $(P<0.02)$, skilled occupation $(P<0.0001)$ and the previous birth of a child with knee deformity from rickets $(P<0.001)$. The mother's cultural perceptions of treatment for childhood rickets associated knee deformities was significantly affected by age $(P<0.001)$, education, $(P<0.001)$, skilled occupation $(P<0.000)$, history of knee deformity $(P<0.04)$ and mothers with children diagnosed to have knee deformity $(P<0.004)$. Lack of finance, poor compliance to treatment, too long treatment periods, lack of information on where to seek for treatment and unaffordable treatment were among the important factors affecting completeness of treatment of knee deformity due to rickets. In conclusion, the awareness of mothers about rickets in Nigeria is still very low. It is a major reason for late presentation or complete failure to seek for adequate treatment of the knee deformity due to rickets. Increase and sustain public health enlightenment programmes are necessary for prevention. Health policy should incorporate free surgical fees for the established knee deformity to encourage community participation in the management of the condition.
\end{abstract}

Key words: rickets, knee deformity, culture, perception, prevention, treatment, Nigeria

\section{Introduction}

Knee deformity is defined as an alteration in the normal anatomical alignment and angulations of the bones comprising the knee joint thereby compromising the normal congruity of the joints (Pettifor, 2004). Angular deformities about the knee are of great importance to parents and these become most apparent when the child begins to walk. In Nigeria, many children develop nutritional rickets. In some communities, up to $15 \%$ of children are affected. In a case-control study of rickets in Nigeria, $15 \%$ of rachitic children had a first-degree relative with rickets while only $3 \%$ of control subjects had an affected relative (P. Fischer unpubl.). Although there is no information on the incidence of the disease, a prevalence figure of $9 \%$ with clinical rickets was reported from a community study of children $<3$ years living in Jos, Nigeria. A figure of $2.4 \%$ for overt rickets and $15 \%$ for suggestive rickets has been reported from Maiduguri, Nigeria (Akpede et al., 1999). In furtherance to the rickets as a major health problem, Oginni et al. (2003) have reported a frequency of 1-2 active rickets per week presenting to the Wesley Guilds Hospital at the Ilesa Unit of the Obafemi Awolowo University Teaching Hospital Complex in Ile Ife, Nigeria.

The commonest cause of persistent knee deformity in children worldwide is rickets (Thacher, 2003). Nutritional rickets is still the commonest cause of knee deformity in developing countries, Nigeria inclusive, as compared to developed countries where there has been a dramatic decline in the prevalence of the condition since the discovery of vitamin D and the role of ultra violet light in its prevention (Thacher et al., 1999). Rickets is defined as a metabolic disorder of childhood characterized by overproduction of osteoid tissue, deficient osteoid calcification with associated skeletal deformities and growth disturbances. Defective bone mineralization, bone pain, weakness and eventually pathological fracture may occur (Calmar \& Vinci, 2002). Rickets presents most commonly between the ages of 6-36 months, which coincides, with the period of rapid growth and commencement of weight bearing (Oginni et al., 2003).

Although a number of studies of rickets have been carried internationally and locally, 
none has looked into the knowledge and cultural perception of the local communities. The aim of this study was therefore, to assess the knowledge and cultural perceptions of mothers towards knee deformity due to rickets in Ile-Ife, Nigeria. The specific objectives were to assess the knowledge of mother's on the causes of knee deformities, the aetiology of rickets; factors influencing the treatment completeness and cultural perceptions of treatment for rickets associated knee deformity.

\section{Materials and Methods}

\section{Study area}

The study was conducted in Ife Central Local Government in Ile-Ife, Osun State, Nigeria. The study area lies at longitude 432 ' $\mathrm{E}$ and latitude $7^{0} 29^{\prime} \mathrm{N}$. The major occupations of the inhabitants include farming, public service, artisan and trading. The population is multiethnic, consisting mainly of Yoruba, Ibo and Hausa. The population of Ife Central from the National Population Commission was 96,580. There were 146 localities in the local government with 22,055 households, 48,560 males and 48,020 females.

\section{Study design and data collection}

The study was a descriptive cross-sectional type. The study population consisted of all mothers above the age of 20 years, who attended the outpatient clinics at the Urban Comprehensive Health Centre in Eleyele, Enuwa Primary Health Care in Ile-Ife, Obafemi Awolowo University Health Centre, and Obafemi Awolowo Teaching Hospital Complex in Ile- Ife. The sample size was determined using the Armittage and Perry formula of single proportion (Reisner et al., 1989). The prevalence was taken to be $50 \%$ because no previous study had been done on the prevalence of the mother's knowledge about knee deformity in rickets in Nigeria.

A simple random probability sampling technique was used. Randomization was done by the use of computer soft ware (MS Excel 5.0) without any bias for religion, tribe, race or culture. Data collection using a pre-tested semi-structured questionnaire was done from $1^{\text {st }}$ August to $29^{\text {th }}$ September 2007. Information sought included (i) socio-demographic characteristics of themothers and their husbands; (ii) mother's knowledge on the aetiology of knee deformities; (iii) knowledge on rickets; and (iv) cultural treatment perceptions of rickets.

\section{Ethical considerations}

An informed consent was obtained from each subject. The medical review and ethical board of each study centre approved the study protocol.

\section{Data analysis}

Data were analyzed using the Statistical Package for Social Sciences (SPSS) software version 11.0. Univariate analysis of the socio-demographic data of the respondents and bivariate analysis was used to assess association between variables including Chi-square and Analysis of variance (ANOVA). A confidence interval of $95 \%$ was chosen with an error margin of $5 \%$ and a $p$ value $<0.05$ was considered significant.

\section{Results}

A total of 464 questionnaires were administered, of which 403 were completed giving a return rate of $86.9 \%$. There were $298(73.9 \%)$ women $<40$ years and $105(26.1 \%)$ were in the $5^{\text {th }}$ decades or older. The mothers' religion practices were Christianity $272(67.5 \%)$, Islam 121 (30.0\%) and Traditional $10(2.5 \%)$. The highest level of education attended were primary 177 (43.9\%), secondary $149(37.0 \%)$, and tertiary 32 (7.9\%). Forty-five (11.2\%) mothers had no formal education. The major tribes included Yoruba (77.4\%), Igbo (14.4\%) and Hausa (3.7\%). Other tribes accounted for the remaining $4.5 \%$. The subjects were engaged in public service 141 $(35.0 \%)$, farming $123(30.5 \%)$, and as housewives $67(16.7 \%)$. Other occupations included tailoring $39(9.7 \%)$, news broadcasting $21(5.2 \%)$, custom officers $7(1.7 \%)$ and medical practitioners 5 $(1.2 \%)$.

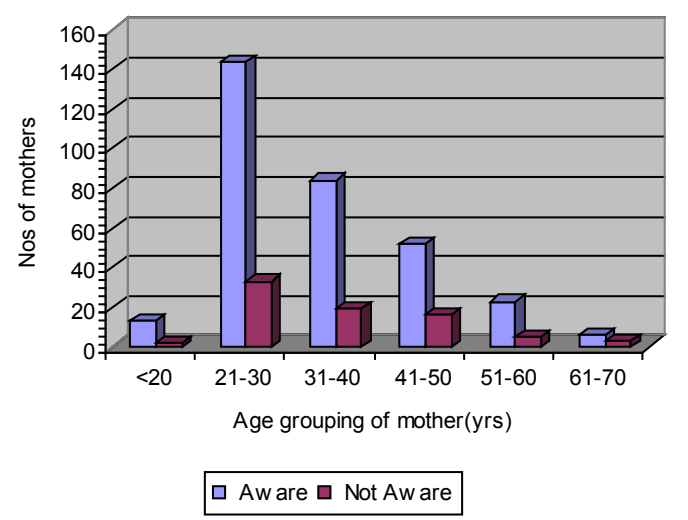

Figure1: Awareness of mothers (by age group) about children with knee deformities

Among mothers in the child bearing age group, $241(59.8 \%)$ were aware of children with knee 
deformity as compared with $54(13.4 \%)$ who were not aware (Figure1). This level of awareness however was not significantly different from those in the older age group where $81(20.1 \%)$ mothers were aware $\left(\chi^{2}=0.811, \mathrm{df}=5, P>0.368\right)$. Seventy-four mothers $(18.4 \%)$ had a previous history of knee deformity and 326 (80.9\%) never had any knee deformity. Of these 74 mothers, $58(78.4 \%)$ had the onset of their knee deformity in childhood.

A total of sixty-one (15.1\%) mothers had children with knee deformity and they were also found to have a statistically significant lower educational level as compared with those with children without knee deformity $\left(\chi^{2}=12.829\right.$, $\mathrm{df}=1, P<0.001)$. Unskilled mothers were found to be related to those who had children with knee deformity $\left(X^{2}=2.278\right.$, df $\left.=1, P<0.026\right)$. Factors such as age $\left(\chi^{2}=5.553, \mathrm{df}=6, P>0.475\right)$, religion $\left(\chi^{2}=2.653, \mathrm{df}=2, P>0.265\right)$ and tribe of the mother $\left(\chi^{2}=2.362, \mathrm{df}=3, P>0.501\right)$ were not related to knee deformity. ANOVA indicated that the significant factors were the level of education $(P<0.007)$, the skilled occupation of the mothers, $(P<0.002)$ and the previous delivery of a child with knee deformity $(P<0.001)$.

Table 1: Perceived causes of knee deformity due to rickets among respondents $(\mathrm{N}=403)$

\begin{tabular}{llr}
\hline \multicolumn{1}{c}{ Response } & \multicolumn{1}{c}{ Yes (\%) } & No (\%) \\
\hline Early walking & $93(23.1 \%)$ & $228(56.3 \%)$ \\
Obesity & $122(30.5 \%)$ & $198(49.1 \%)$ \\
Infections & $194(48.1 \%)$ & $128(31.8 \%)$ \\
Cancer & $205(50.9 \%)$ & $117(29.0 \%)$ \\
Rickets & $148(36.7 \%)$ & $174(43.2 \%)$ \\
Nutritional & $194(48.1 \%)$ & $128(31.8 \%)$ \\
Hereditary & $217(53.8 \%)$ & $105(26.1 \%)$ \\
Injury & $80(19.8 \%)$ & $242(60.0 \%)$ \\
Ancestral & $7(1.7 \%)$ & $316(78.4 \%)$ \\
\hline
\end{tabular}

N.B: There are respondents who did not know anything about certain etiological factor thus resulted in their skipping.

Of the 403 women, 147 (36.5\%) were aware of rickets and 253(62.8\%) were not aware. However, only $91(22.6 \%)$ knew the meaning of rickets and $56(38.1 \%)$ of those who were aware had wrong perceptions of rickets' knowledge. The level of education of mothers and that of their husbands were significantly positive contributory factors to the awareness of rickets. Eighty-seven $(21.8 \%)$ of the educated parents were aware of rickets as compared to four $(1 \%)$ of the uneducated $\left(\chi^{2}=\right.$ $10.369, \mathrm{df}=1, P<0.001$ ).

A large number of the mothers that were aware of knee deformity were informed mainly through friends and relatives (40\%) than through health talks $(10 \%)$, electronic media $(24 \%)$ and prints $(17 \%)$.

Table 2: Knowledge of mothers on the aetiology of rickets $(\mathrm{N}=403)$

\begin{tabular}{lll}
\hline Response & Yes (\%) & No (\%) \\
\hline $\begin{array}{l}\text { Inadequate } \\
\text { exposure to }\end{array}$ & $86(21.3 \%)$ & $61(15.1 \%)$ \\
$\begin{array}{l}\text { sunshine } \\
\text { Inadequate intake } \\
\text { of protein }\end{array}$ & $58(14.4 \%)$ & $89(22.1 \%)$ \\
$\begin{array}{l}\text { Inadequate intake } \\
\text { of Calcium }\end{array}$ & $85(21.1 \%)$ & $62(15.4 \%)$ \\
$\begin{array}{l}\text { Premature birth } \\
\text { Exclusive breast }\end{array}$ & $68(16.9 \%)$ & $79(19.6 \%)$ \\
feeding & $0.0(0.0 \%)$ & $147(36.5 \%)$ \\
Hereditary & $30(7.4 \%)$ & $117(29.0 \%)$ \\
$\begin{array}{l}\text { Dark Complexion } \\
\text { Multiple birth }\end{array}$ & $30(7.4 \%)$ & $117(29.0 \%)$ \\
Inadequate child & $10(2.5 \%)$ & $137(34.0 \%)$ \\
spacing & $74(18.4 \%)$ & $73(18.1 \%)$ \\
\hline
\end{tabular}

N.B: There are mothers who did not know about certain aetiological factors thus resulted in their skipping.

Rickets aetiology was wrongly perceived to be bone infection $(48.1 \%)$, cancer $(50.9 \%)$ and hereditary $(53.8 \%)$ (Table 1$)$. Very low proportions of mothers were knowledgeable of the aetiology of rickets. Inadequate exposure to sunshine and inadequate intake of Calcium was mentioned by less than a quarter of the respondents (Table 2 ).

Table 3: The mother's cultural perception of treatment for knee deformity in rickets $(\mathrm{N}=403)$

\begin{tabular}{lll}
\hline Response & Yes (\%) & No (\%) \\
\hline $\begin{array}{l}\text { Increased } \\
\text { exposure to } \\
\text { sunshine }\end{array}$ & $85(21.1 \%)$ & $239(59.3 \%)$ \\
$\begin{array}{l}\text { Increased } \\
\text { intake of } \\
\text { protein/ }\end{array}$ & $200(49.6 \%)$ & $124(30.8 \%)$ \\
calcium & & \\
$\begin{array}{l}\text { Exclusive } \\
\text { breastfeeding }\end{array}$ & $206(51.1 \%)$ & $118(29.3 \%)$ \\
$\begin{array}{l}\text { Plaster of Paris } \\
\text { Knee Brace }\end{array}$ & $227(56.3)$ & $97(24.1 \%)$ \\
$\begin{array}{l}\text { Surgery } \\
\text { Spontaneous }\end{array}$ & $70(17.4 \%)$ & $254(63.0 \%)$ \\
Correction & 285(21.1\%) & $239(59.3 \%)$ \\
Traditional & $194(48.1 \%)$ & $44(10.9 \%)$ \\
\hline
\end{tabular}

N.B: There are respondents who did not know about certain aetiological factors thus resulted in their skipping. 
About one-fifth of the mothers knew increased exposure to sunshine and surgery were forms of major treatment. Spontaneous correction, use of Plaster of Paris, exclusive breastfeeding, increased intake of protein/calcium was perceived by the majority of mothers as the best treatment for knee deformity. Increased exposure to sunshine, knee brace and surgical operations were poorly perceived as among the appropriate treatment of knee deformity (Table 3). The factors that enhance cultural perception of treatment positively included non-active childbearing mothers age group ( $P$ $<0.001)$, education $(P<0.001)$, skilled occupation $(P<0.000)$, previous history of knee deformity $(P<0.04)$ and mothers with children who had knee deformity $(P<0.004)$. However, religion $(P>0.868)$ and tribe $(P>0.494)$ were not significant factors. The factors that affect the completeness of treatment for knee deformity due to rickets included lack of finance, poor compliance with treatment; too long period of treatment, lack of information on where to seek for treatment and treatment too expensive (Figure 2).

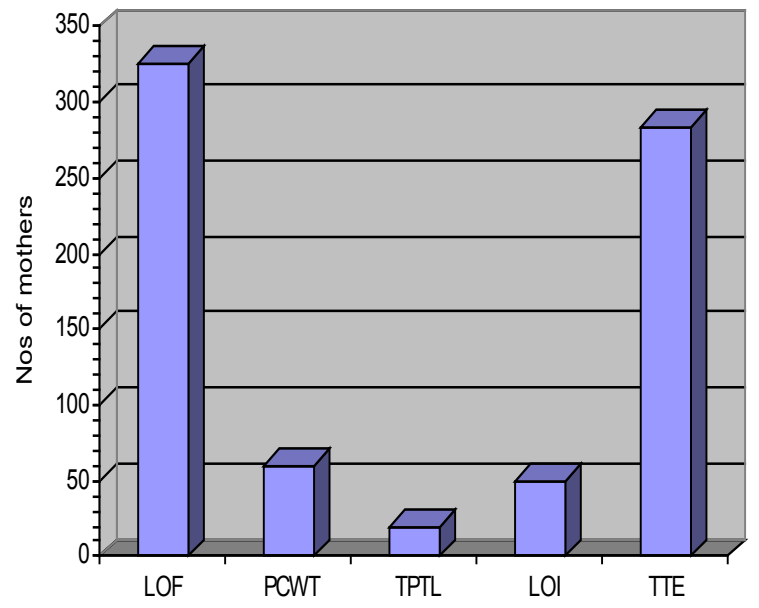

Figure 2: The factors affecting completeness of treatment of knee deformity in rickets

Legend: $\mathrm{LOF}=$ Lack of finance; $\mathrm{PCWT}=$ Poor compliance with treatment; TPTL=Treatment period too long; LOI=Lack of information on where to seek for treatment; TTE -Treatment too expensive

\section{Discussion}

Nutritional rickets remains a major public health problem in many countries where social and cultural practices may preclude adequate skin exposure to ultraviolet radiation and thus predisposes to vitamin D deficiency (Thacher et al., 2000). Like in our study, tribe and religion were not found to be significant factors as children with rickets have been reported among all Nigerian tribes in among both Christians and Moslems (Oginni et al., 2003; Graff et al., 2004). Older respondents (>50 years old) were less aware of children with knee deformity as compared to women in the active childbearing age group. This might be due to improved utilization of the antenatal care services, increased educational health talks and modernized health care services available to the younger mothers. The mothers who had past medical history of knee deformity were dated back to the childhood life. Paediatrics population requires maximal attention in programmes aimed at preventing knee deformity. Education was the strongest predictive factor for having adequate knowledge on knee deformity and aetiology of rickets among Nigerian mothers. It was significantly higher among the educated and the skilled mothers whose husbands were educated. Similar findings have been reported in other studies (Magnus et al., 1996; WHR, 1997; Drozdzowska et al., 2004).

The occurrence of children with knee deformity was higher among unskilled than the skilled mothers. This is likely to be due to the skilled mother's knowledge on improved feeding practices, adequate childbirth spacing and higher social economic status resulting in ability to provide fortified milk with calcium for their children. The provision of outdoor recreational centres in day-care centres where the children of skilled mothers are often taken care could increase their exposure to early morning sunshine. Ignorance, poverty and negative cultural perceptions about the aetiology and treatment of rickets in the community are more preponderance among the unskilled mothers.

The majority of mothers who were aware of rickets were those who had a child or relatives with knee deformity due to rickets. The quality of the information passed through friends and relatives is often inadequate, incorrect and laden with cultural fables. It could explain the reason for the defective Nigerians mother's knowledge on the aetiology, actual meaning of rickets and associated poor treatment perceptions. In addition, prints editorial board comments, television / radio programmes and news publications do not consider rickets in the communities as of public health importance. Previous research on rickets emphasized mainly laboratory and clinical investigations (Thacher et al., 1999; Oginni et al., 2003; Cesur et al., 2003; Pettifor, 2004). Our study has shown the number of mothers that were aware through health talks 
is very small. The cultural orientation of mothers could be positively altered by appropriate health education through public enlightenments on electronic media and prints.

In Nigeria, dietary calcium deficiency is a second cause of rickets especially in older children outside infancy (Oginni et al., 1996; Gartner \& Greer, 2003). Hereditary, cancer and bone infection were considered by the majority of the women in Ile-Ife as the cause of knee deformities in children. The mothers with a history of previous delivery of a child with knee deformity exhibited higher positive adequate treatment perception when compared to those without such children, irrespective of their level of education. The cares seeking tendencies of such mothers exposed them to wider consultations and acquire knowledge on the deformity and treatment options of rickets.

Rickets has been described perhaps to be the most significant complication of exclusive breast-feeding. The consequence was the current recommendation of vitamin D supplementation for all exclusively breastfed children (Cesur et al., 2003). However, we found no single mother, the health workers inclusive, who was aware of the aforementioned fact. Only a few of the Nigerian mothers were aware of dark skin to be significant predisposing factors to development of rickets. The modern day scientific knowledge on rickets negates the majority of mothers cultural perception, their beliefs about dark skin and exclusive breast feeding practice (Pettifor, 2004) which were taught to confer protection against rickets. Other factors poorly associated with aetiology of rickets were inadequate intake of protein, inadequate intake of calcium, premature birth, multiple birth and inadequate child spacing. We observed these poor perception was more predominant among the unskilled, uneducated and poverty ridden mothers. It thus emphasized the need for the health sector to be more active in enlightening the community on bone health.

The poor awareness of the available medical and surgical modalities of management for knee deformity related to rickets could explain the community poor utilization of appropriate health facilities. The mothers believed in traditional modality for treating knee deformity of rickets may be linked to late presentation for orthopaedics' care. An increased level of community awareness will result in prompt early diagnosis and prevention of cases of rickets in evolution before knee deformity becomes revealed clinically. Since high cost of treatment and prolonged period of treatment were among the major hindrance of seeking medical care, surgical treatment of knee deformity related to rickets should be free in order to improve child bone health and welfare in resource-limited countries such as Nigeria.

Received 21 January 2008

Revised 19 November 2008

Accepted 20 November 2008

\section{References}

Akpede, G.O., Omotara, B.A. \& Ambe, J.P. (1999) Rickets and deprivation: a Nigerian study. Journal of Royal Society of Health 119, 216-222.

Calmar, E.A. \& Vinci, R.J. (2002) The anatomy and physiology of bone fracture and healing. Journal of Clinical Pediatrics Emergency Medicine 3, 85-93.

Cesur, Y., Caksen, H., Gundem, A., Kirimi, E. \& Odabas, D. (2003) Comparison of low and high dose vitamin $\mathrm{D}$ treatment in nutritional vitamin $\mathrm{D}$ deficiency rickets. Journal of Pediatrics Endocrinology $\mathcal{E}$ Metabolism 16, 1105-1109.

Drozdzowska, B., Pluskiewika, W. \& Skiba, M. (2004) Knowledge about osteoporosis in a cohort of polish females; the influence of age, level of education and personal experiences. Osteoporosis International 15, 645-648.

Gartner, L.M. \& Greer, F.R. (2003) Section on Breastfeeding and Committee on Nutrition. American Academy of Pediatrics. Prevention of rickets and vitamin D deficiency: new guidelines for vitamin D intake. Journal of Pediatrics 908-910.

Graff, M., Thacher, T.D., Fischer, P.R., Stadler, D., Pam, S.D., Pettifor, J.M., Isichei, C.O. \& Abrams, S.A. (2004) Calcium absorption in Nigerian children with rickets. American Journal of Clinical Nutrition 80, 1415-1421.

Magnus, J.H., Joakimsen, R.M., Bemtsen, G.K., Tollan, A. \& Soogaard, A.J. (1996) What do Norwegian women and men know about osteoporosis? Osteoporosis International 6, 32-36.

Oginni, L.M., Worsfold, M., Oyelami, O.A., Sharp, C.A., Powell, D.E. \& Davie, M.W. 
(1996) Etiology of rickets in Nigerian children. Journal of Pediatrics 128, 692.

Oginni, L.M., Sharp, C.A., Badru, O.S., Risteli, J., Davie, M.W.J. \& Worsfold, M. (2003) Radiological and biochemical resolution of nutritional rickets with calcium. Archive of Diseases in Children 88,812817.

Pettifor, J.M. (2004) Nutritional rickets: deficiency of vitamin D, calcium, or both? American Journal of Clinical Nutrition 80, S1725- 1729

Reisner, E.R., Perry, C.A. \& Armitage, M. (1989) Teaching Course Content through mentoring. American Journal of Education 99, 568-586.

Thacher, T.D., Fischer, P.R., Pettifor, J.M., Lawson, J.O., Isichei, C.O., Reading,
J.C. \& Chan, G.M. (1999) A comparison of calcium, vitamin $\mathrm{D}$, or both for nutritional rickets in Nigerian children. The New England Journal of Medicine 341, 563-568.

Thacher, T.D., Fischer, P.R., Pettifor, J.M., Lawson, J.O., Isichei, C. \& Chan, G.M. (2000) Case-control study of factors associated with nutritional rickets in Nigerian children. Journal of Paediatrics 137,367-373.

Thacher, T.D. (2003) Calcium-deficiency rickets. Endocrinology Development 6,105-125.

WHR (1997) Executive summary, conquering suffering, enriching humanity life expectancy, health expectancy. World Health Reports (Archive 1997-2000). 